\section{Intestinal Obstruction Due to Fluid Accumulation in an Abdominal Hernia: A Rare Complication of Colonic Lavage}

Colonic washout prior to colonoscopy, using polyethylene glycolbased electrolyte solutions (PEG-ELS), has proved to be safe and effective (1). However, complications, both major and minor, have been described $(2-4)$. Recently, we observed a life-threatening complication using this technique.

An asymptomatic 88-year-old woman was referred to our department with iron-deficiency anemia. The clinical examination showed a large, incarcerated hernia within a cholecystectomy scar. On the barium swallow, the terminal ileum and ascending colon were found to be in the hernial sac (Figure 1). The patient was submitted to a colonic washout with PEG-ELS in preparation for colonoscopy. After drinking two liters, the patient developed obstructive symptoms. The clinical examination showed diffuse tenderness of the abdomen and muscle guarding. A radiograph revealed air-fluid levels in dilated small intestinal loops (Figure 2). An emergency laparatomy was performed to rule out strangulation. There were no signs of diminished viability of the bowel, and no resection was needed. The hernial sac was reduced, and the hernial ring, allowing the passage of three fingers, was closed. After a lengthy postoperative recovery, the patient is in good health one year later.

We think that the weight of the fluid accumulated in the incarcerated loops induced sufficient traction on the mesentery to cause obstruction. In a similar case report, obstruction was due to overinsufflation by the endoscopist (5). Although this complication is rare, its severity should be kept in mind by all colonoscopists. Patients with an abdominal hernia, especially when it is incarcerated, deserve extra attention when submitted to colonic lavage.

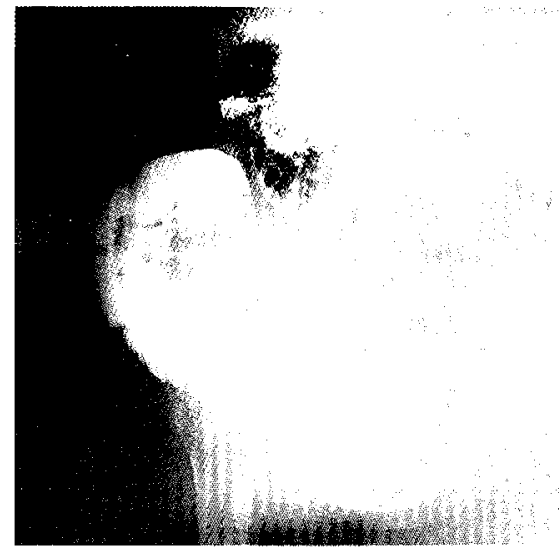

Figure 1: Incarcerated incisional hernia due to an old cholecystectomy, on barium swallow. The terminal ifeum and the ascending colon are found in the hernial sac.

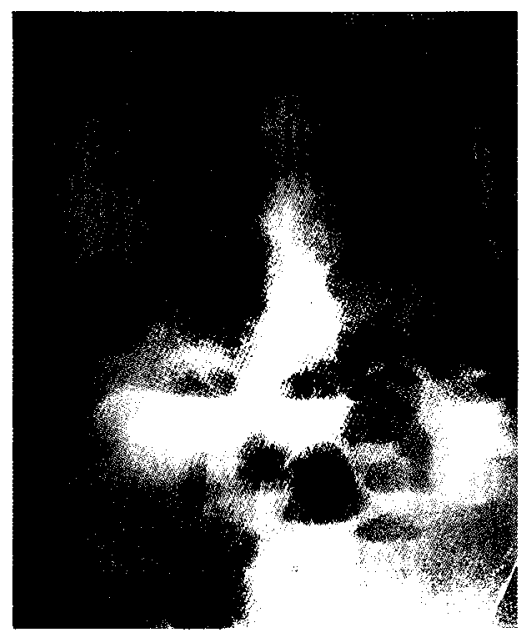

Figure 2: During lavage, the patien developed an intestnal obstruction. The plain abdominal radiograph shows air-fluid levels in dilated small intestinal loops. 


\section{References}

1. Dipalma JA, Brady CE: Colon cleansing for diagnostic and surgical procedures: polyethylene glycol electrolyte lavage solution. Am J Gastroenterol 1989; 84: 1008-1016.

2. Bronowicki JP, Brigard MA, Vigneron J: Solution de PEG pour lavage intestinal: salée ou non salée. Gastroenterol Clin Biol $1990 ; 14: 268-269$

3. Di Fibo G, Gizzi G, Calo G, et al.: Comparison of a new colon lavage solution (Iso-Guiliani) with a standard preparation for colonoscopy: a randomised study. Endoscopy 1990; 22: 214216.
4. Vilieu M, Rytkonen M: Golytely preparation for colonoscopy: 1.5 liters is enough for outpatients. Endoscopy 1990; 22: 168-170.

5. Rees BJ, Williams LA: Incarceration of hernia after colonoscopy. Lancet 1977; 8007: 371.

W. Hutse, A. Mast, V. Van Maele, W. Pauwels

Department of Gastroenterology, Algemeen Ziekenhuis

H. Familie, Ghent, Belgium

Corresponding Author

W. Hutse, M.D.

Department of Gastroenterology, Algemeen Ziekenhuis H. Familie, Groenebriel 1, 9000 Ghent, Belgium 